\title{
Uranium Annealing Analysis
}

\author{
James King \\ Michael Benson
}

September 2015

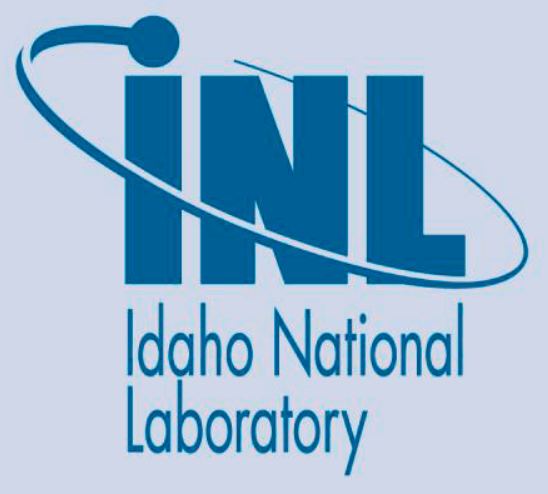

The INL is a U.S. Department of Energy National Laboratory operated by Battelle Energy Alliance 


\section{DISCLAIMER}

Neither the U.S. Government nor any agency thereof, nor any of their employees, makes any warranty, expressed or implied, or assumes any legal liability or responsibility for the accuracy, completeness, or usefulness, of any information, apparatus, product, or process disclosed, or represents that its use would not infringe privately owned rights. References herein to any specific commercial product, process, or service by trade name, trade mark, manufacturer, or otherwise, does not necessarily constitute or imply its endorsement, recommendation, or favoring by the U.S. Government or any agency thereof. The views and opinions of authors expressed herein do not necessarily state or reflect those of the U.S. Government or any agency thereof. Being provided this document, directly or indirectly, shall not be construed to constitute a governmental export license or authorization.

\section{GENERATED INFORMATION - UNLIMITED RIGHTS}

This document contains, at least in part, Generated Information - Unlimited Rights arising under 13-CR-13 between TerraPower, LLC, and Battelle Energy Alliance, LLC. 
INL/EXT-17--41916

Revision 0

\title{
Uranium Annealing Analysis
}

\author{
James King \\ Michael Benson
}

\begin{abstract}
Idaho National Laboratory
Fuel Development

Idaho Falls, Idaho 83415
\end{abstract}

http://www.inl.gov

\author{
Prepared for \\ TerraPower, LLC \\ Under CRADA 13CRADA13 \\ And DOE Idaho Operations Office \\ Contract DE-AC07-05ID14517
}





\section{Fuel Development}

\section{Uranium Annealing Analysis}

INL/EXT17-41916

Revision 1

September 2015

Approved by:

Name

Date

Title [optional]

Name

Title [optional]

Date

Name

Title [optional]

Date

Name

Date

Title [optional] 


\section{SUMMARY}

This report describes tests completed at INL on depleted uranium samples of surplus shield block from the Zero Power Physics Reactor (ZPPR). Tests

involved annealing individual samples in molten salt for periods ranging from 30

minutes to 4 hours, with variations on conditions as described in the report. Some samples were also left as cast. After annealing, samples were cooled either in water or air. Annealing and as-cast samples were measured and analyzed for hardness, oxide layer, and rind thickness. 


\section{CONTENTS}

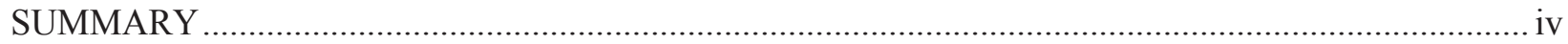

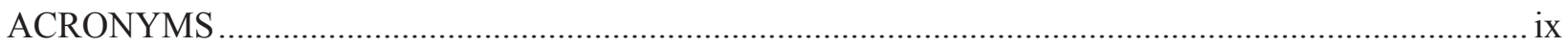

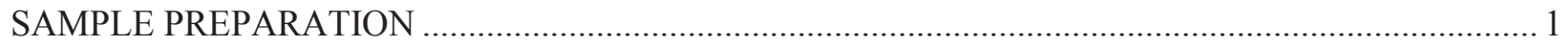

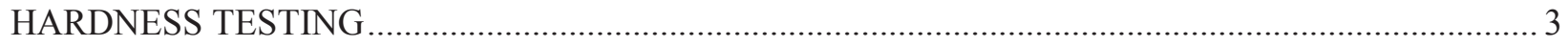

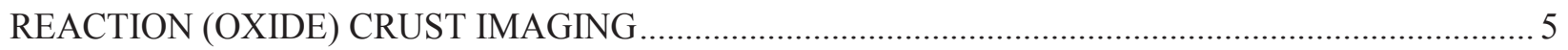

NEW Na-, Li-, AND K-CARBONATE SALT EXAMINATION ....................................................... 15

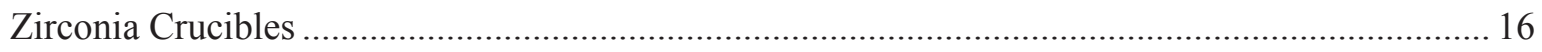

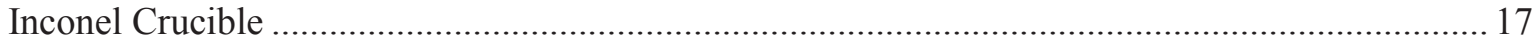

\section{FIGURES}

Figure 1. DU cube after cleaning, prior to the salt annealing step....................................................... 1

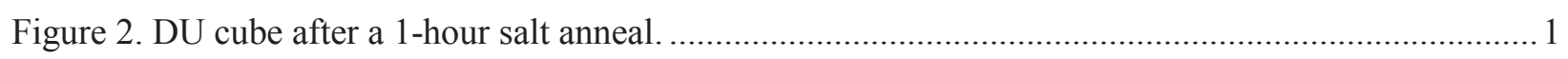

Figure 3. Crucibles used for annealing test. Crucible on the right coated in AREMCO Products

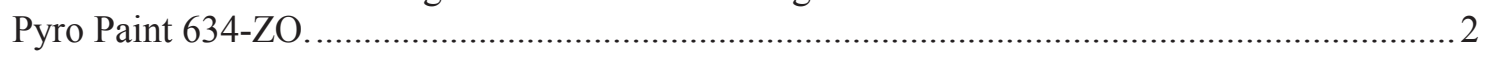

Figure 4. DU cube wrapped in stainless steel (SS) wire. The SS wire was held in the salt bath by a quartz tube to prevent a circuit from developing with the crucible......................................... 2

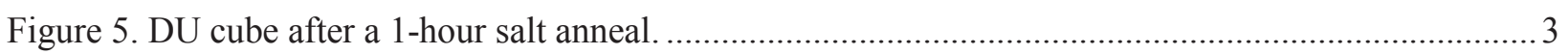

Figure 6. Indentation showing elastic stretching of surrounding area. ................................................. 4

Figure 7. Composite image of DU Cube \#1 (untreated) …...................................................................... 7

Figure 8. Composite image of DU Cube \#6, treated in the salt bath for 30 minutes and quenched

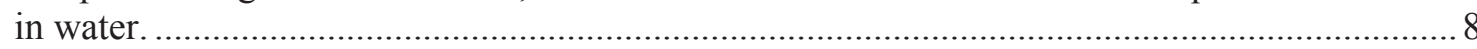

Figure 9. Composite image of DU Cube \#5, treated in the salt bath for 1 hour and quenched in

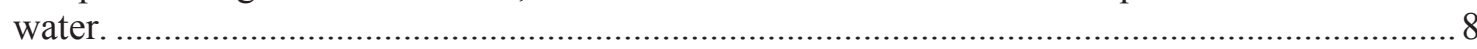

Figure 10. Composite image of DU Cube \#3, treated in the salt bath for 1 hour followed by air cooling.

Figure 11. Composite image of DU Cube \#7, treated in the salt bath within a crucible coated with AREMCO Products Pyro Paint 634-ZO for 1 hour and quenched in water.

Figure 12. Composite image of DU Cube \#9, suspended for 1 hour in the salt bath using SS wire and quartz tube to prevent developing a circuit with the crucible. After annealing the samples was quenched in water.

Figure 13. Composite image of DU Cube \#2, treated in the salt bath for 2 hours followed by air cooling.

Figure 14. Composite image of DU Cube \#4, treated in the salt bath for 4 hours followed by air cooling. 
Figure 15. Image from the bottom right corner of untreated DU Cube \#1.

Figure 16. Image from the bottom right corner of DU Cube \#6, treated in the salt bath for 30 minutes and quenched in water.

Figure 17. Image from the bottom right corner of DU Cube \#5, treated in the salt bath for 1 hour and quenched in water.

Figure 18. Image from the bottom right corner of DU Cube \#3, treated in the salt bath for 1 hour followed by air cooling.

Figure 19. Image from the bottom right corner of DU Cube \#7, treated in the salt bath within a crucible coated with AREMCO Products Pyro Paint 634-ZO for 1 hour and quenched in water.

Figure 20. Image from the bottom right corner of DU Cube \#9, suspended for 1 hour in the salt bath (using SS wire and a quartz tube to limit contact with the crucible) and quenched in water.

Figure 21. Image from the bottom right corner of DU Cube \#2, treated in the salt bath for 2 hours followed by air cooling.

Figure 22. Image from the bottom right corner of DU Cube \#4, treated in the salt bath for 4 hours followed by air cooling.

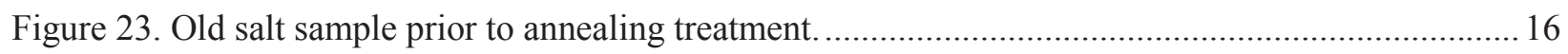

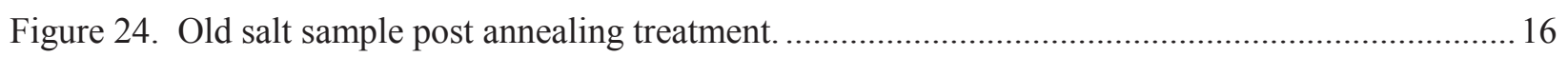

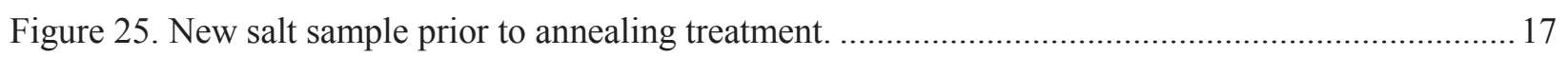

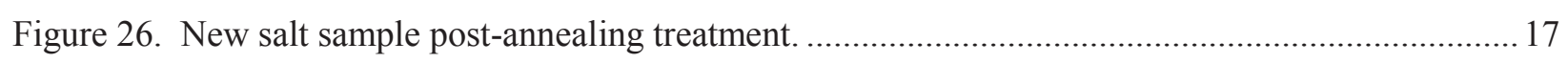

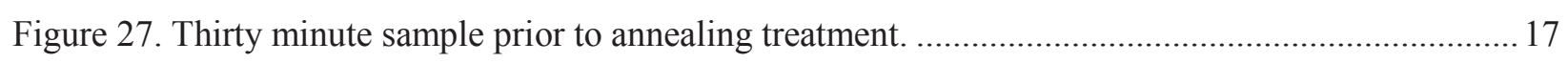

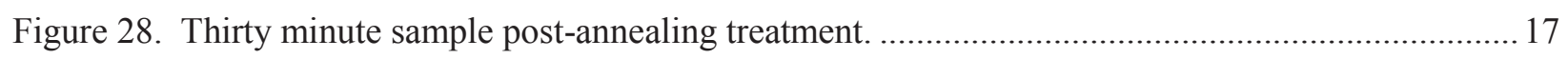

\section{TABLES}

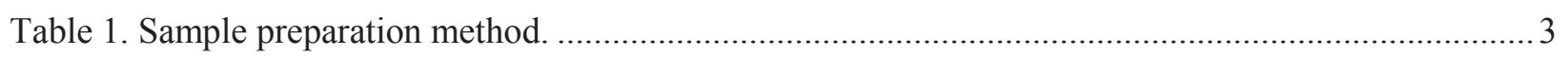

Table 2. Measured hardness values. Each measurement is an average of points. ...................................... 5

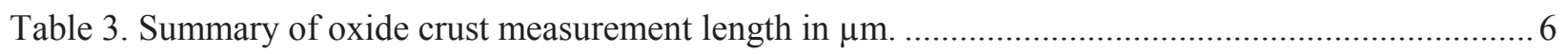

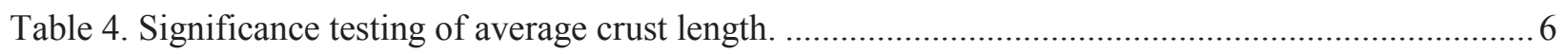

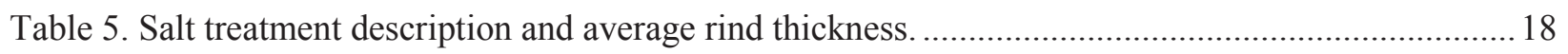




\section{ACRONYMS}

DU depleted uranium

SD

standard deviation

SEM

standard error of the mean

SS

stainless steel

ZPPR

Zero Power Physics Reactor 


\section{Analysis of Uranium Billet Material \\ SAMPLE PREPARATION}

Initially, four $1 / 2$ in. cubic samples were cut from the waste Zero Power Physics Reactor (ZPPR) shield block material after removing an extrusion billet from the uranium block. Three of these samples were annealed in molten carbonate salt, the same salt as was used in the large salt bath for extrusion, at $650^{\circ} \mathrm{C}$ for 1 hour, 2 hours, and 4 hours, respectively. Inconel crucibles were used to contain the salt and uranium samples in an air furnace. After annealing for the appropriate time, the samples were removed and allowed to cool in air. A fourth sample was not annealed. For the annealed samples, an obvious oxide crust layer was observed.

After the initial experiment, a second set of two $1 / 2$ in. cubic samples were prepared for annealing in molten salt at $650^{\circ} \mathrm{C}$ for 30 minutes and 1 hour. After annealing, these samples were quenched in water. Figure 1 shows an example of the depleted uranium (DU) cube after cleaning prior to the salt annealing step. Figure 2 shows the same DU cube after a 1-hour salt anneal.

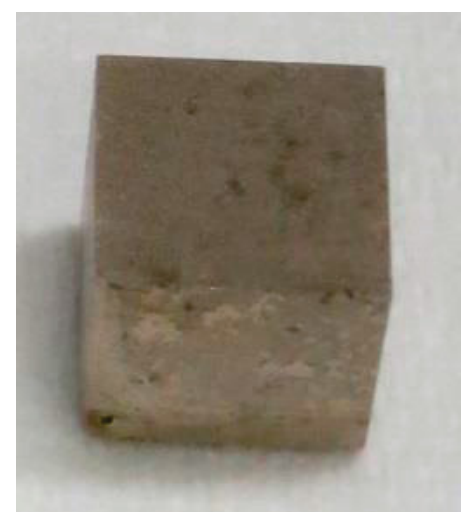

Figure 1. DU cube after cleaning, prior to the salt annealing step.

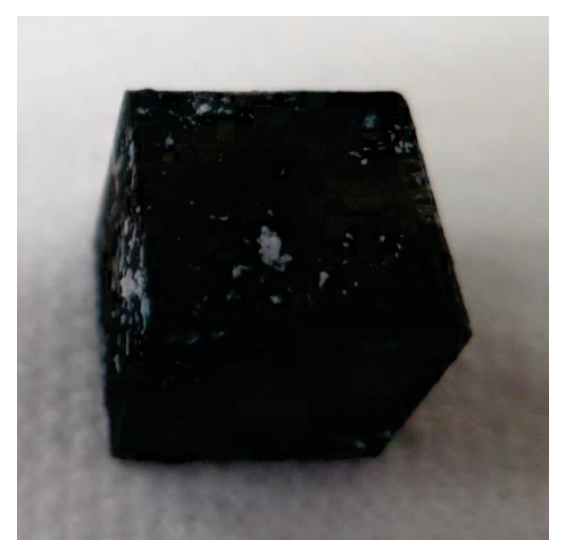

Figure 2. DU cube after a 1-hour salt anneal.

A third annealing experiment was performed by placing two $1 / 2$ in. cubic samples in Cartecsal molten salt for 1 hour at $650^{\circ} \mathrm{C}$. In this experiment, one cube was placed in a crucible coated with AREMCO Products Pyro Paint 634-ZO (designated as "1 hour [coated crucible]"), and one cube was suspended in 
the salt using stainless steel wire (Figure 3) to limit contact with the crucible (designated as "1 hour [suspended]"). After annealing, these samples were quenched in water.

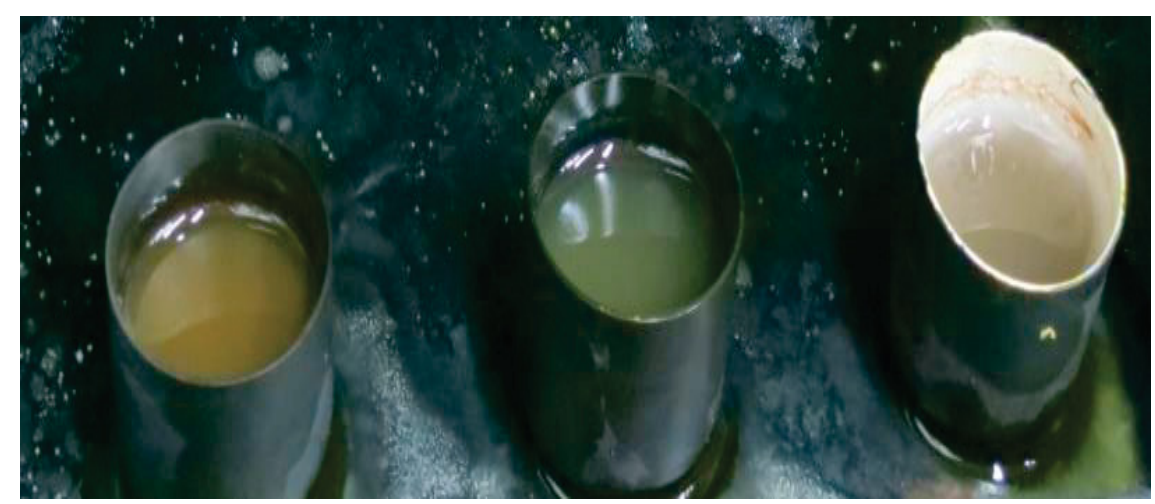

Figure 3. Crucibles used for annealing test. Crucible on the right coated in AREMCO Products Pyro Paint 634-ZO.

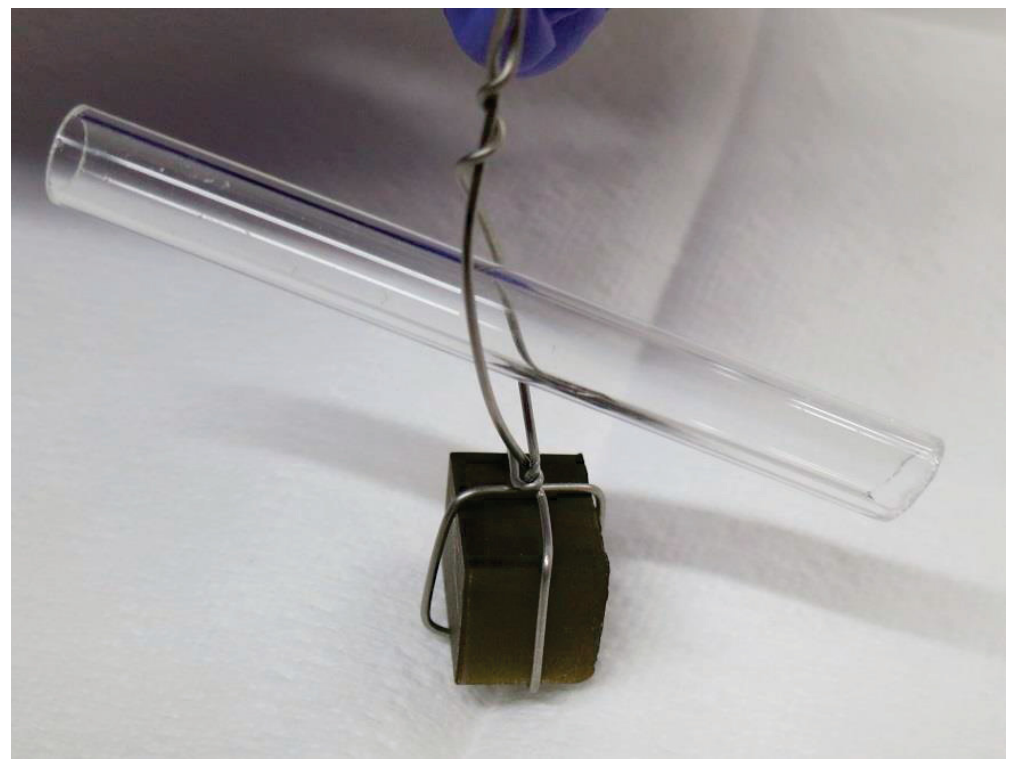

Figure 4. DU cube wrapped in stainless steel (SS) wire. The SS wire was held in the salt bath by a quartz tube to prevent a circuit from developing with the crucible.

All samples were mounted in 1.25-in. phenolic rings with EpoThin (Buehler) epoxy resin. After curing, the samples were polished with progressively smaller abrasives using a Buehler AutoMet autopolisher. Samples were ground flat using 240 -grit $\mathrm{SiC}$ grinding paper. This was followed by polishing with 320-, 600-, and 800-grit $\mathrm{SiC}$ grinding papers and 3- $\mu \mathrm{m}$ (TexMet C) paper, then 1- $\mu \mathrm{m}$ (MicroCloth) polycrystalline diamond suspensions. An example of the resulting samples is shown in Figure 4. This DU cube is the same cube shown in Figures 1 and 2. A detailed description of the sample polishing method is shown in Table 1. 


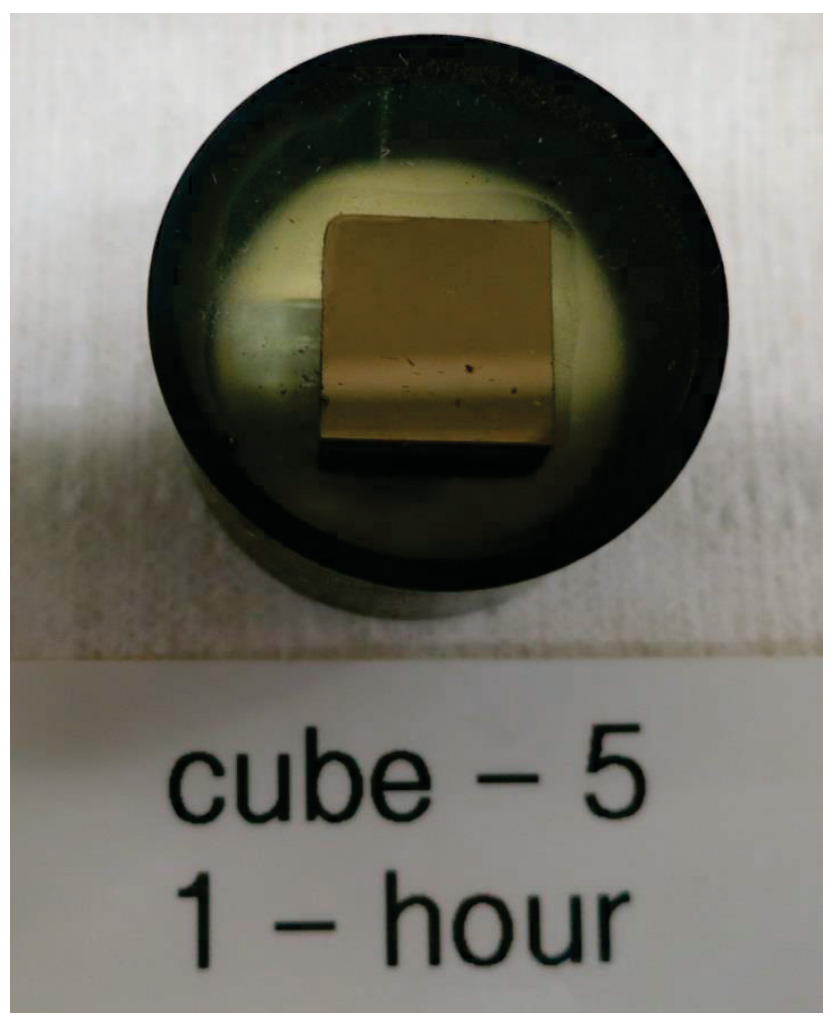

Figure 5. DU cube after a 1-hour salt anneal.

Table 1. Sample preparation method.

\begin{tabular}{|l|l|l|l|l|l|l|}
\hline Abrasive & $\begin{array}{l}\text { Abrasive } \\
\text { Size }\end{array}$ & $\begin{array}{l}\text { Polishing } \\
\text { Cloth }\end{array}$ & $\begin{array}{l}\text { Time } \\
(\mathrm{min})\end{array}$ & $\begin{array}{l}\text { Force } \\
(\mathrm{lb} .)\end{array}$ & $\begin{array}{l}\text { Platten } \\
\text { RPM }\end{array}$ & $\begin{array}{l}\text { Platten/Head } \\
\text { Direction }\end{array}$ \\
\hline $\mathrm{SiC}$ & 240 grit & -- & $2: 00$ & 5 & 180 & Opposite \\
\hline $\mathrm{SiC}$ & 320 grit & -- & $1: 30$ & 5 & 180 & Opposite \\
\hline $\mathrm{SiC}$ & 600 grit & -- & $5: 00^{*}$ & 4 & 150 & Opposite \\
\hline $\mathrm{SiC}$ & 800 grit & -- & $2: 30$ & 4 & 150 & Opposite \\
\hline $\begin{array}{l}\text { Polycrystalline } \\
\text { diamond }\end{array}$ & $3 \mu \mathrm{m}$ & TexMet C & $6: 00$ & 4 & 120 & Complementary \\
\hline $\begin{array}{l}\text { Polycrystalline } \\
\text { diamond }\end{array}$ & $1 \mu \mathrm{m}$ & MicroCloth & $6: 00$ & 4 & 120 & Complementary \\
\hline
\end{tabular}

* Grinding paper replaced after 2:30.

\section{HARDNESS TESTING}

To do the microhardness testing, 200 gram force (gf) was used with a 13-second dwell time. Multiple series of 15 points were taken on each sample. This allowed for a large number of points for the average, while still allowing for the worst data points to be thrown out. In all of the series, no more than 2 points were discounted in each single series of 15. Typical hardness values for uranium range from 196 to 250 $\mathrm{Pa}$ on the Vickers scale. 
The measurements were difficult due to stretching around the indents. This is shown in Figure 5. Although the indent is well-defined, stretching lines are observed below the indent. These lines are not scratches from the polishing, and were not present prior to the indentation. In many cases, one of the vertices was not well-defined. Due to the stretching, the hardness values cannot be considered absolute. Regardless, they are in the correct range for uranium, so they are probably close to the absolute hardness value. The stretching, and therefore the difficulty in determining the vertices, was present in all four samples. Although the absolute value cannot be guaranteed, all of the data points were measured in the same manner, so the comparison between samples should be valid.

In order to avoid the sample stretching, the suggestion was made to use less force to do the measurements. This was not successful. Less force (50 gf) for the indents caused less stretching, but the smaller indent was still affected by the stretching.

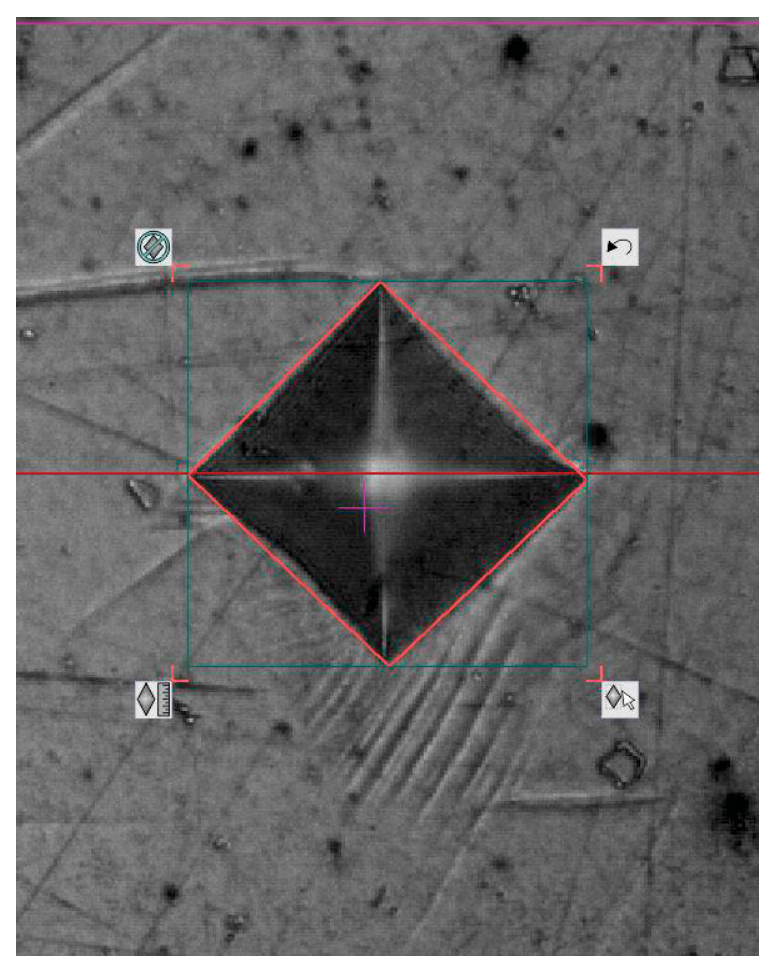

Figure 6. Indentation showing elastic stretching of surrounding area.

Table 2 lists the measured values for the hardness testing. Unless specified, the measurements were taken from the middle of the sample. The 1-hour treated sample was tested across the sample to determine if there was a heating/cooling difference between the outer block and the middle. Although the left side is slightly harder, in the hardness scale this is still a small change. 
Table 2. Measured hardness values. Each measurement is an average of points.

\begin{tabular}{|l|l|l|l|l|}
\hline Sample* & Measurement 1 & Measurement 2 & Measurement 3 & Measurement 4 \\
\hline Untreated & 215 & 219 & 223 & \\
\hline 1 hour & 256 -left & 238 -middle & 229 -middle & 229-right \\
\hline 2 hour & 219 & 215 & --- & --- \\
\hline 4 hour & 222 & 227 & 241 & \\
\hline
\end{tabular}

* All samples cooled in air.

There is a little variation in the hardness values, although given the difficulty in the measurements due to stretching, the differences are likely experimental error. There is essentially no difference in hardness upon heating the samples.

\section{REACTION (OXIDE) CRUST IMAGING}

Polished DU cubes were observed using brightfield microscopy. Images were acquired around the periphery of the samples at $50 \times$ total magnification. Typically, eight images were acquired for the right and the left sides, while six images were acquired along the top and the bottom of the DU cube. After acquisition, the length of the crust layer was measured using Zeiss AxioVision software. To maintain consistency across the many images, the crust layer was measured at specific locations for every image. The span of the image was sub-divided and the crust length was measured and recorded at approximately $1 / 4,1 / 2$, and $3 / 4$ of the total length of the images. The average of the oxide crust length measurements is included in Table 3, along with standard deviation (SD) and standard error of the mean (SEM). When no oxide crust layer existed at the predefined measurement locations, no value was recorded for that measurement. It is possible that it could have been removed during sample preparation, or that the presence of pitting or porosity alters the development or occurrence of the oxide crust. These points were not included in the data shown in Table 3.

Hypothesis testing (assuming two normally distributed independent populations for the different cubes) in general indicates that the average crust measurements for each cube are significantly different from each other at a 95\% confidence level, as shown in Table 4 . The suspended DU cube was similar in measured oxide crust length to the water-quenched DU cube. There was not enough evidence to reject the null hypothesis between the 1-hour "coated-crucible" sample and the air-cooled samples annealed for 1 and 2 hours, respectively. The large SD for the 1-hour "coated-crucible" DU cube contributes to this result. It is assumed that the significant differences observed between the air-cooled and water-cooled 1hour treatments are due to the difference in cooling after annealing in the salt bath. 
Table 3. Summary of oxide crust measurement length in $\mu \mathrm{m}$.

\begin{tabular}{|l|l|l|l|}
\hline Sample* & Average & SD & SEM \\
\hline Untreated & None & -- & -- \\
\hline 30 min $\left(\mathrm{H}_{2} \mathrm{O}\right)$ & 21.78 & 4.87 & 0.54 \\
\hline 1 hour $\left(\mathrm{H}_{2} \mathrm{O}\right)$ & 25.48 & 6.26 & 0.81 \\
\hline 1 hour & 27.64 & 5.53 & 0.64 \\
\hline 1 hour (coated crucible $\left./ \mathrm{H}_{2} \mathrm{O}\right)$ & 31.42 & 16.71 & 2.03 \\
\hline 1 hour $\left(\right.$ suspended $\left./ \mathrm{H}_{2} \mathrm{O}\right)$ & 24.78 & 6.93 & 0.87 \\
\hline 2 hours & 35.14 & 7.33 & 0.91 \\
\hline 4 hours & 40.97 & 12.15 & 1.94 \\
\hline
\end{tabular}

* Samples not specified were cooled in air.

Table 4. Significance testing of average crust length.

\begin{tabular}{|c|c|c|c|c|c|}
\hline \multicolumn{2}{|c|}{ Testing Conditions Compared } & p-value* & $\square_{(0.05, \mathrm{df})}$ & $\mathrm{t}^{* *}$ & Result \\
\hline \multirow{6}{*}{$30 \min \left(\mathrm{H}_{2} \mathrm{O}\right)$ vs. } & 1 hour $\left(\mathrm{H}_{2} \mathrm{O}\right)$ & $2.36 \mathrm{E}-04$ & 2.001 & 3.80 & Reject null \\
\hline & 1 hour (air) & $8.48 \mathrm{E}-11$ & 1.993 & 7.00 & Reject null \\
\hline & 1 hour (coated crucible $/ \mathrm{H}_{2} \mathrm{O}$ ) & $2.45 \mathrm{E}-05$ & 1.996 & 4.60 & Reject null \\
\hline & 1 hour (suspended/ $\mathrm{H}_{2} \mathrm{O}$ ) & $4.25 \mathrm{E}-03$ & 1.999 & 2.92 & Reject null \\
\hline & 2 hours & $6.70 \mathrm{E}-23$ & 1.998 & 12.62 & Reject null \\
\hline & 4 hours & $3.16 \mathrm{E}-12$ & 2.024 & 9.50 & Reject null \\
\hline \multirow{5}{*}{1 hour $\left(\mathrm{H}_{2} \mathrm{O}\right)$ vs. } & 1 hour (air) & $3.84 \mathrm{E}-02$ & 2.001 & 2.09 & Reject null \\
\hline & 1 hour (coated crucible $/ \mathrm{H}_{2} \mathrm{O}$ ) & $8.10 \mathrm{E}-03$ & 2.001 & 2.72 & Reject null \\
\hline & 1 hour $\left(\right.$ suspended $\left./ \mathrm{H}_{2} \mathrm{O}\right)$ & $5.57 E-01$ & 2.001 & 0.59 & Accept null \\
\hline & 2 hours & $1.11 \mathrm{E}-12$ & 2.001 & 7.94 & Reject null \\
\hline & 4 hours & $1.47 \mathrm{E}-09$ & 2.024 & 7.35 & Reject null \\
\hline \multirow{4}{*}{1 hour vs. } & 1 hour (coated crucible/ $\mathrm{H}_{2} \mathrm{O}$ ) & $7.50 E-02$ & 1.996 & -1.78 & Accept null \\
\hline & 1 hour (suspended/ $\mathrm{H}_{2} \mathrm{O}$ ) & $1.23 \mathrm{E}-01$ & 1.999 & 2.64 & Reject null \\
\hline & 2 hours & $5.86 \mathrm{E}-10$ & 1.998 & 6.75 & Reject null \\
\hline & 4 hours & 4.81E-08 & 2.024 & -6.51 & Reject null \\
\hline \multirow{3}{*}{$\begin{array}{l}1 \text { hour } \\
\text { (coated } \\
\text { crucible } / \mathrm{H}_{2} \mathrm{O} \text { ) vs. }\end{array}$} & 1 hour (suspended/ $\mathrm{H}_{2} \mathrm{O}$ ) & $3.62 \mathrm{E}-03$ & 1.999 & 3.01 & Reject null \\
\hline & 2 hours & $1.31 E-01$ & 1.998 & 1.68 & Accept null \\
\hline & 4 hours & $1.58 \mathrm{E}-03$ & 2.024 & 3.40 & Reject null \\
\hline \multirow{2}{*}{$\begin{array}{l}1 \text { hour } \\
\text { (suspended/ } \mathrm{H}_{2} \mathrm{O} \text { ) vs. }\end{array}$} & 2 hours & $2.12 \mathrm{E}-13$ & 1.999 & 8.22 & Reject null \\
\hline & 4 hours & $4.76 \mathrm{E}-10$ & 2.024 & 7.59 & Reject null \\
\hline 2 hours vs. & 4 hours & $8.90 \mathrm{E}-03$ & 2.024 & -2.71 & Reject null \\
\hline
\end{tabular}

* For two-tailed student t-test with unequal variance, $\bar{x}_{1}-\bar{x}_{2}=0$.

** Where $t=\frac{\bar{x}_{1}-\bar{x}_{2}}{\sqrt{\frac{s_{1}^{2}}{n_{1}}+\frac{s_{2}{ }^{2}}{n_{2}}}}$ and $\bar{x}_{i}=$ sample average, $s_{i}=$ sample $S D$, and $n_{i}=$ sample size. 
After the oxide crust length measurements were completed, the images were merged using Photoshop. Merged images for each DU cube are shown in Figures 6-12. Spatial distortions in the images occurred in the merging process. Length measurements are shown in red along the periphery in Figures 7-13. As summarized in Table 3, increased time in the salt bath generally resulted in increased oxide crust layer thickness. The untreated billet showed no evidence of an oxide crust (Figure 6). Additionally, the increased time in the salt bath resulted in more abundant and deeper pitting of the billet cubes.

Comparison of 1-hour treated samples suggests that suspending the sample may decrease pitting (Figures 8-11). However, the suspended sample may have interacted with the wire used to suspend it as indicated by the silvery precipitates along the top edge of Figure 11. Additional analysis would be necessary to evaluate whether or not the DU cube interacted with the SS wire. The images from the third experiment (Figures 10, 11, 18, and 19) are more colored in appearance. It is assumed that the coloration was due to increased surface oxidation, as these samples were delayed in analysis as compared with the samples from previous experiments. Indentations from micro-hardness testing, described in the previous section, are observable in Figure 8.

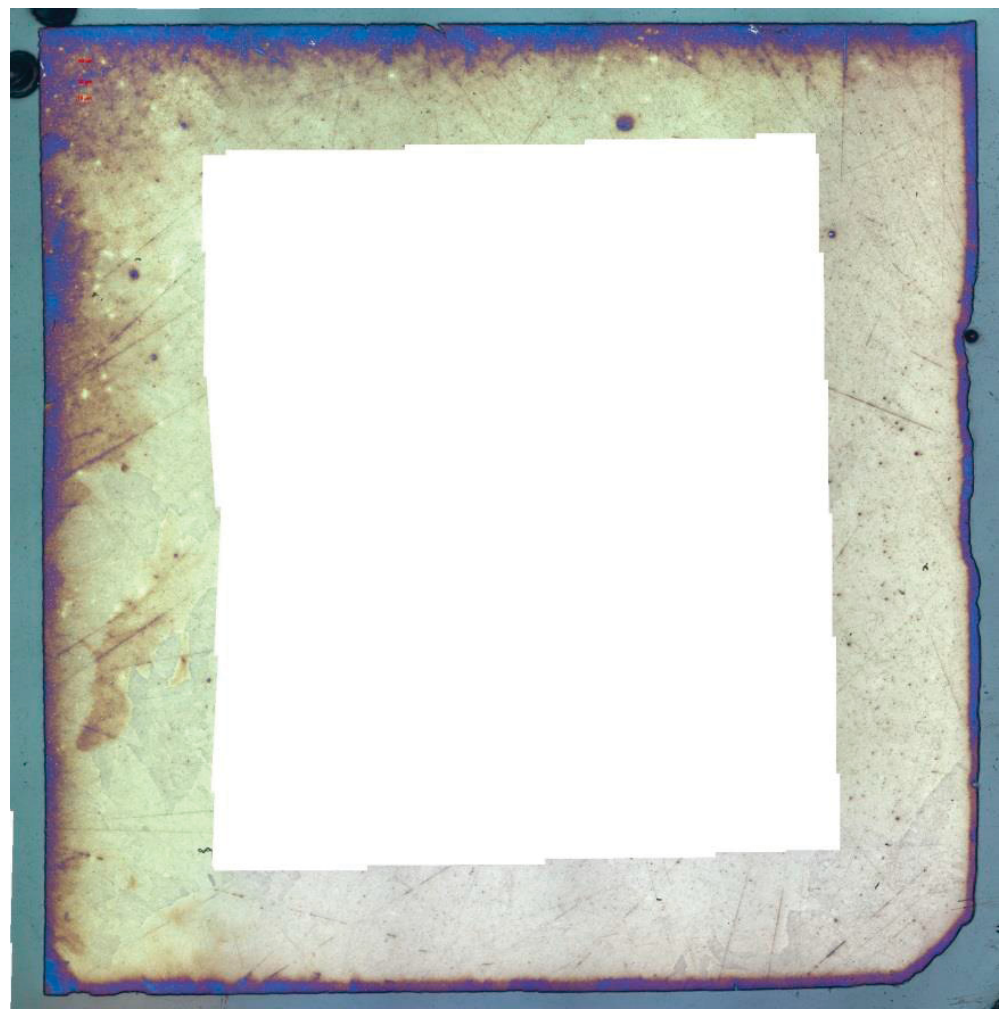

Figure 7. Composite image of DU Cube \#1 (untreated). 


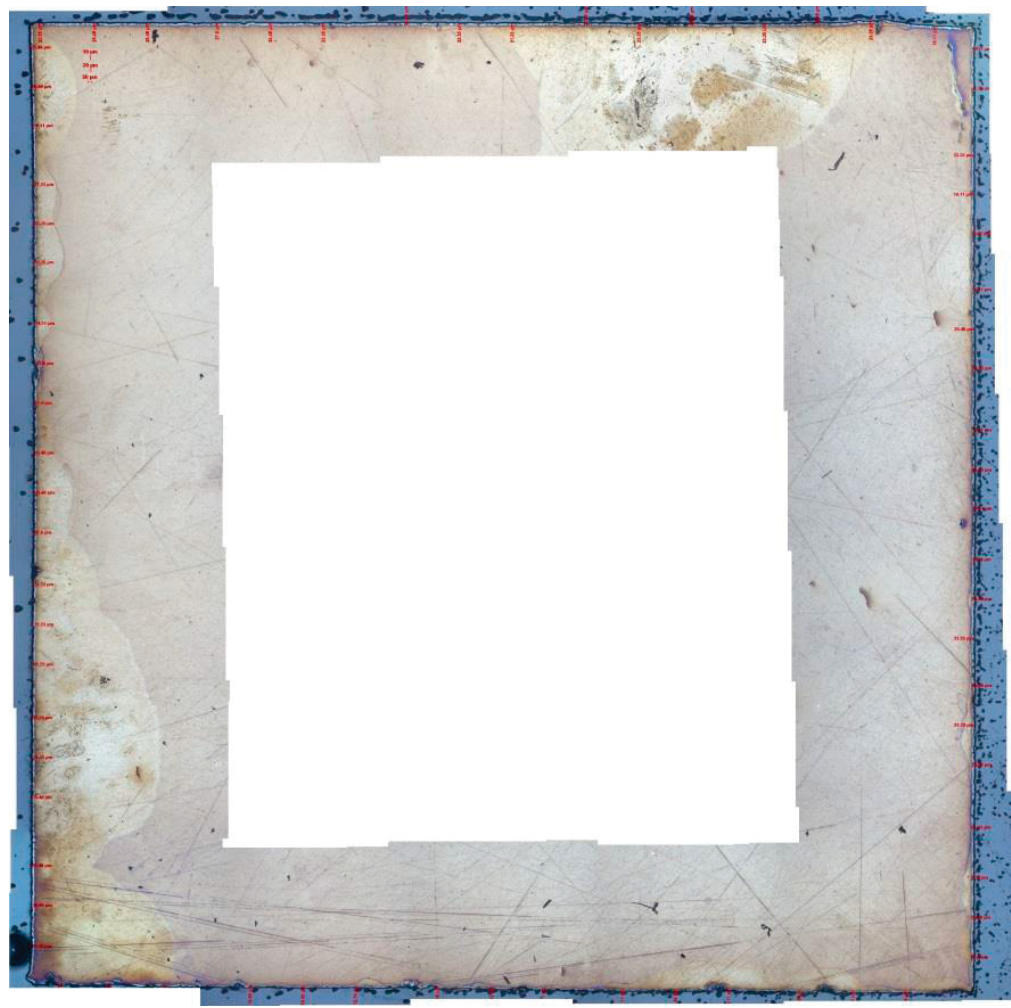

Figure 8. Composite image of DU Cube \#6, treated in the salt bath for 30 minutes and quenched in water.

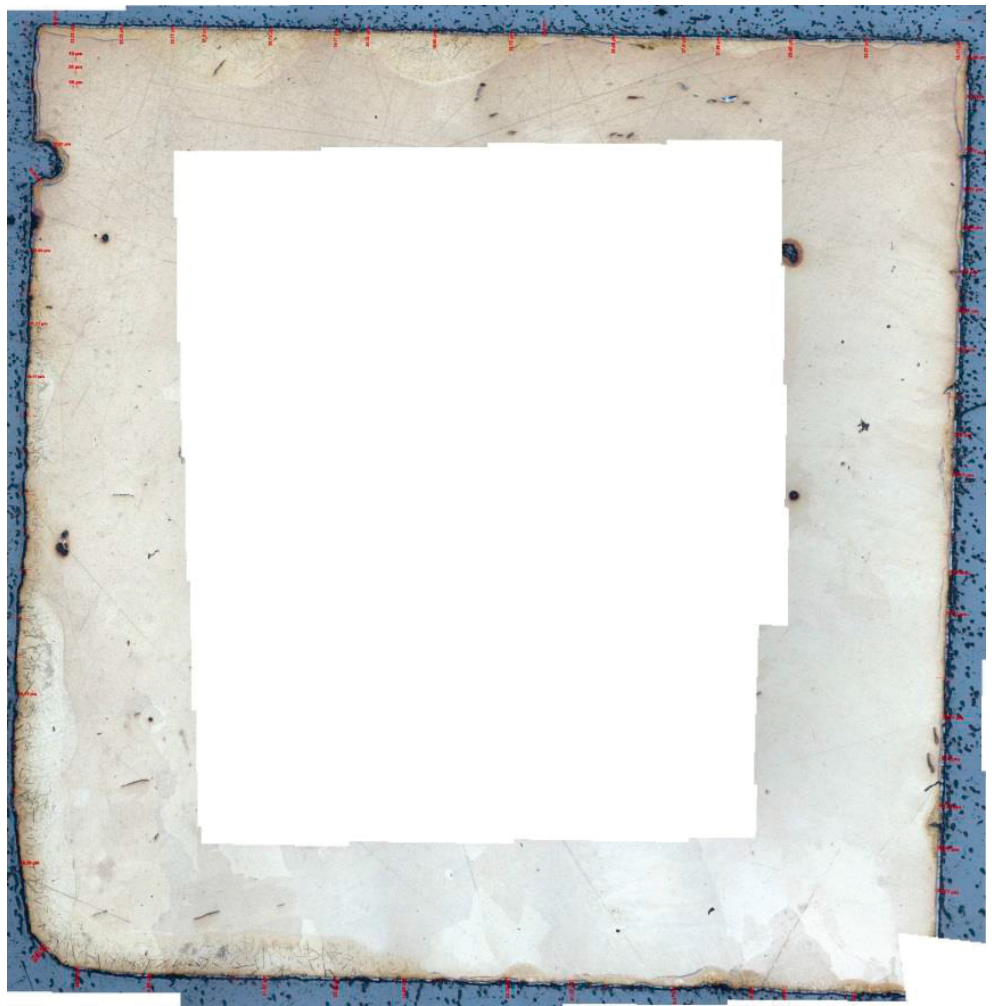

Figure 9. Composite image of DU Cube \#5, treated in the salt bath for 1 hour and quenched in water. 


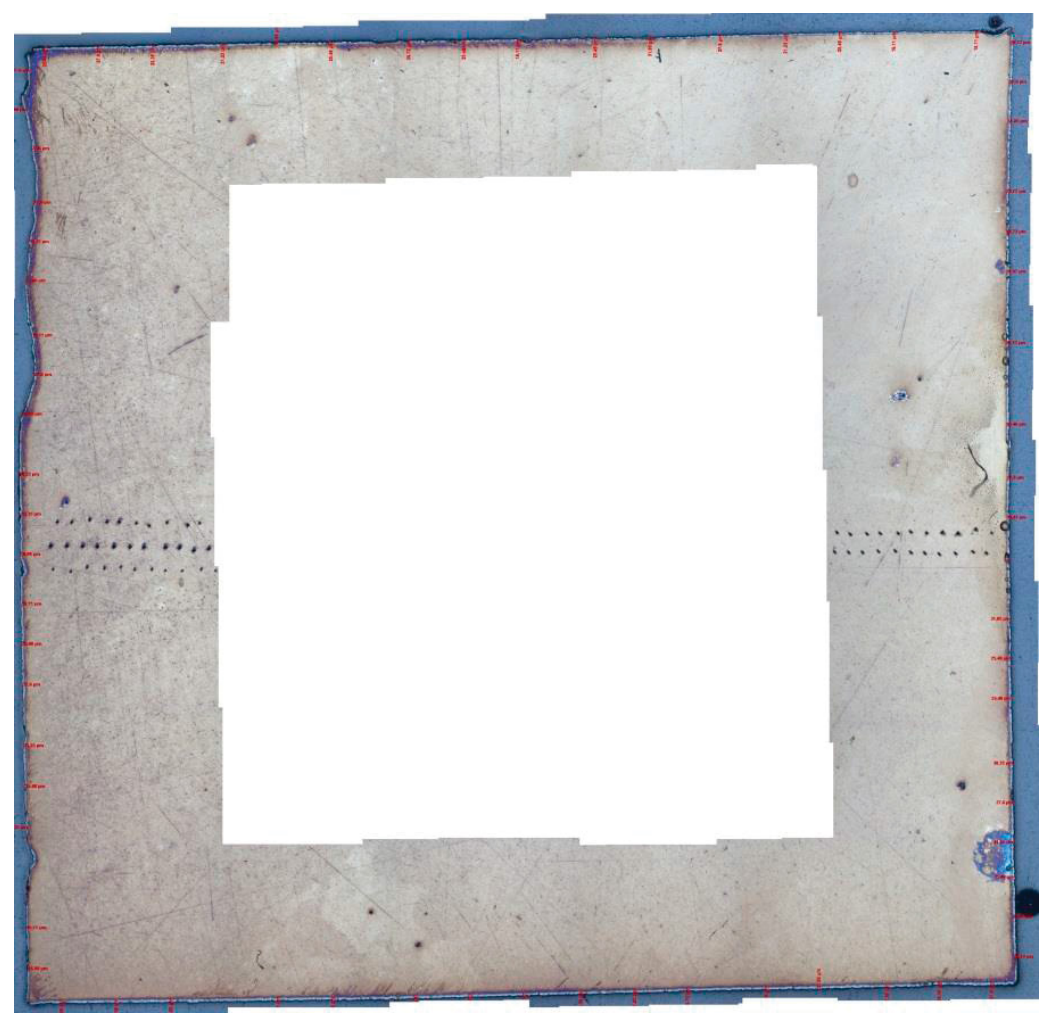

Figure 10. Composite image of DU Cube \#3, treated in the salt bath for 1 hour followed by air cooling.

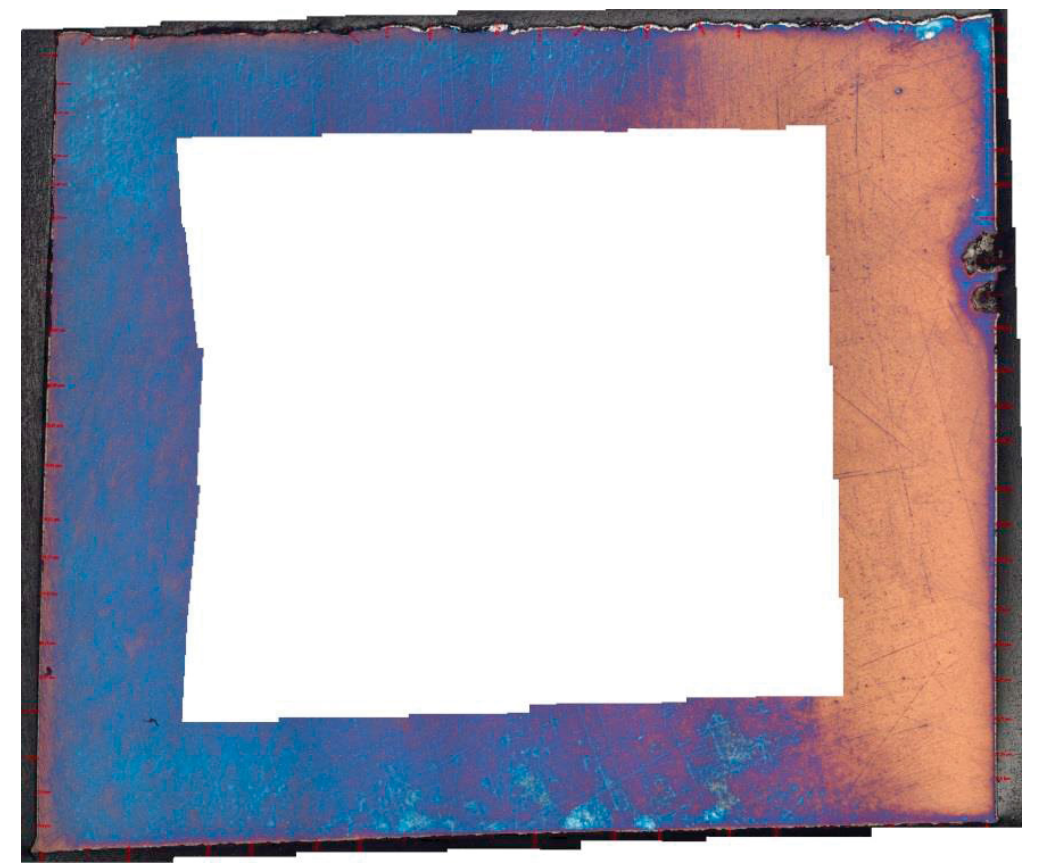

Figure 11. Composite image of DU Cube \#7, treated in the salt bath within a crucible coated with AREMCO Products Pyro Paint 634-ZO for 1 hour and quenched in water. 


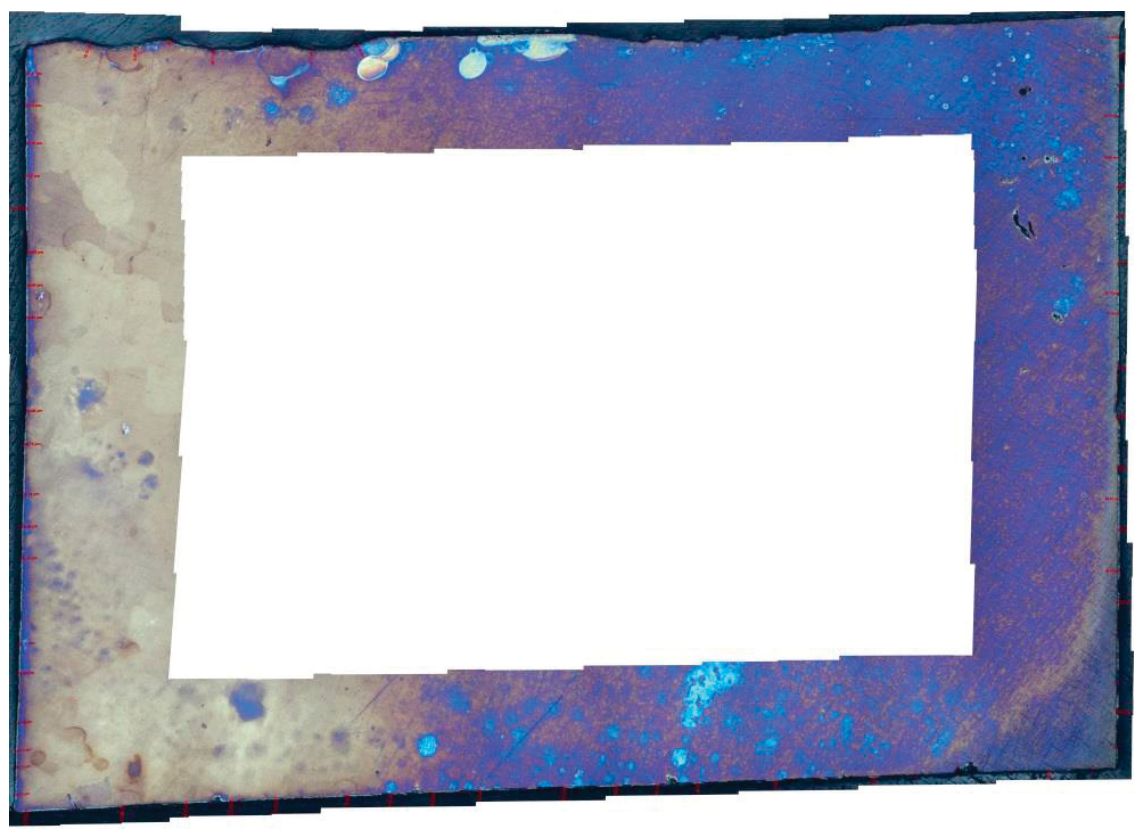

Figure 12. Composite image of DU Cube \#9, suspended for 1 hour in the salt bath using SS wire and quartz tube to prevent developing a circuit with the crucible. After annealing the samples was quenched in water.

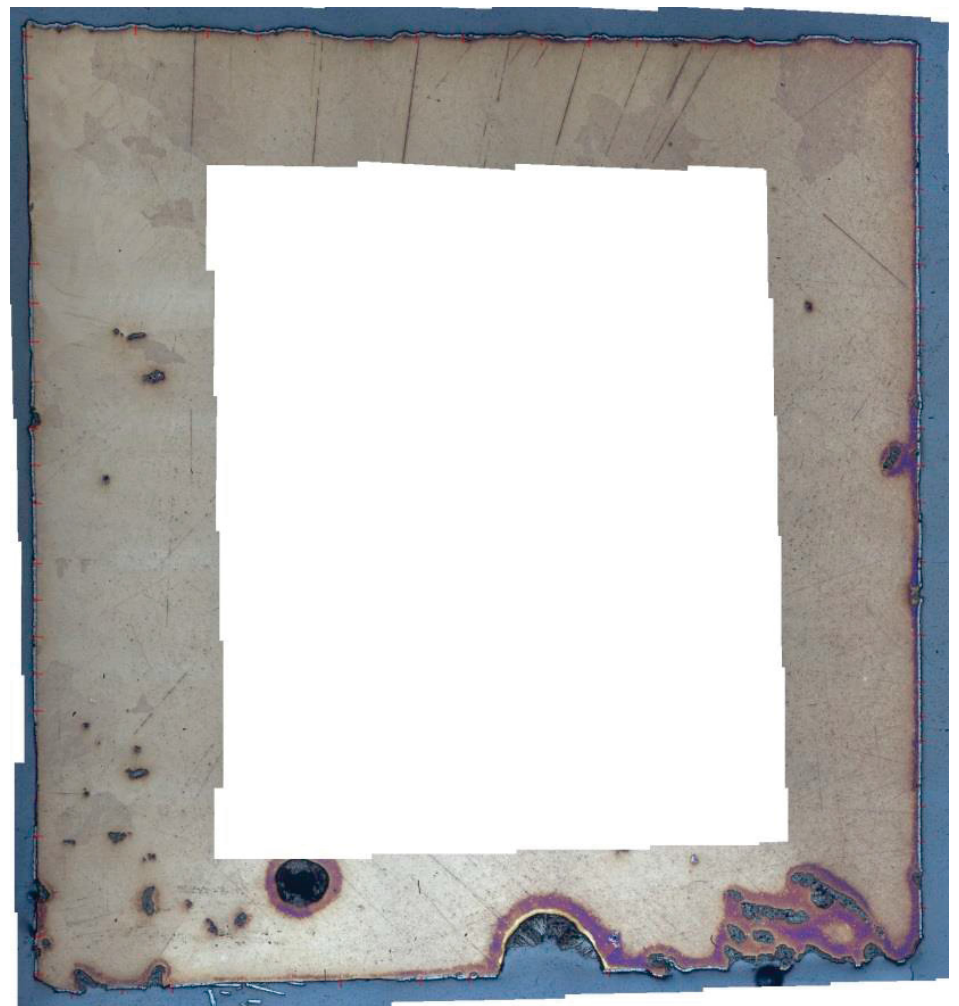

Figure 13. Composite image of DU Cube \#2, treated in the salt bath for 2 hours followed by air cooling. 


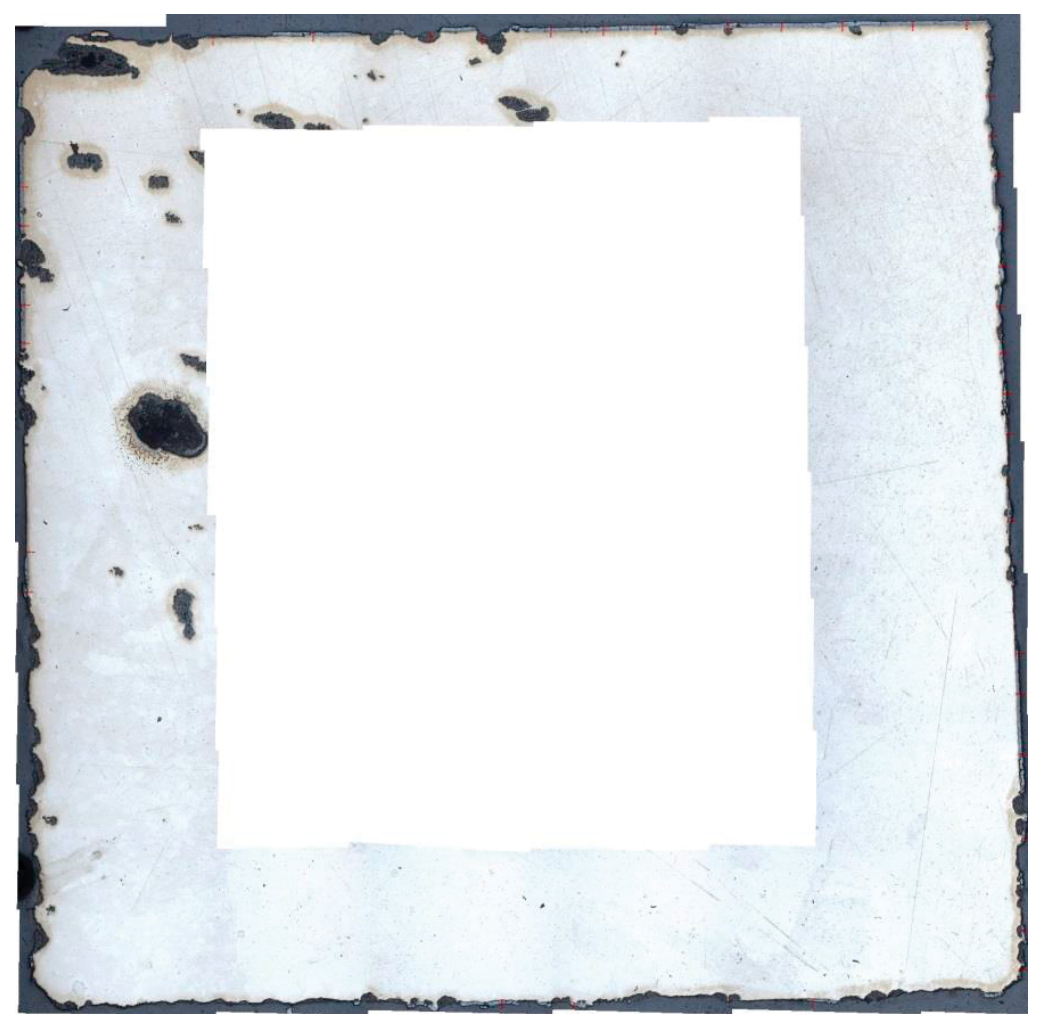

Figure 14. Composite image of DU Cube \#4, treated in the salt bath for 4 hours followed by air cooling.

Figures 15-21 show images of a corner of the DU cubes and are representative of the images acquired prior to merging. These images show the presence of oxidized uranium on a polished surface, in addition to the oxide crust around the edges, as exemplified by the purple shading along the edges of the cube in Figure 14. This observation of could be due to a variety of factors, including differences in topography due to polishing procedure, different material properties in this region due to reaction, or increased nucleation of oxides at the edge of the material. It is likely that the white speckles observed in Figure 20 are due to incomplete cleaning of the sample surface prior to image acquisition. 


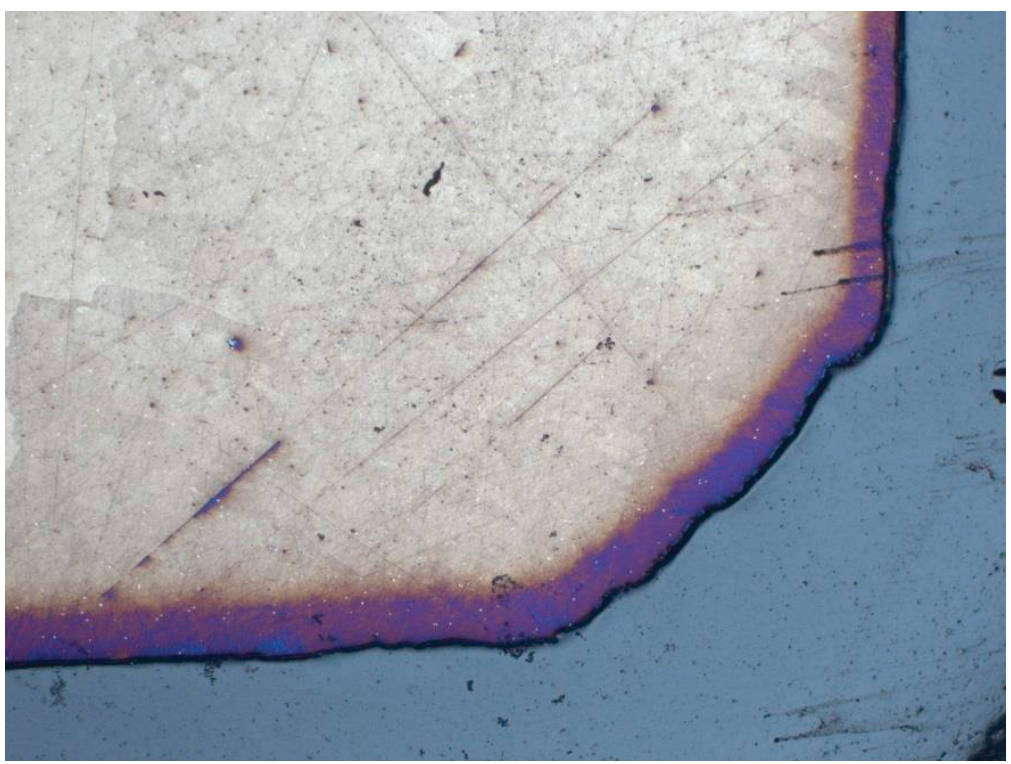

Figure 15. Image from the bottom right corner of untreated DU Cube \#1.

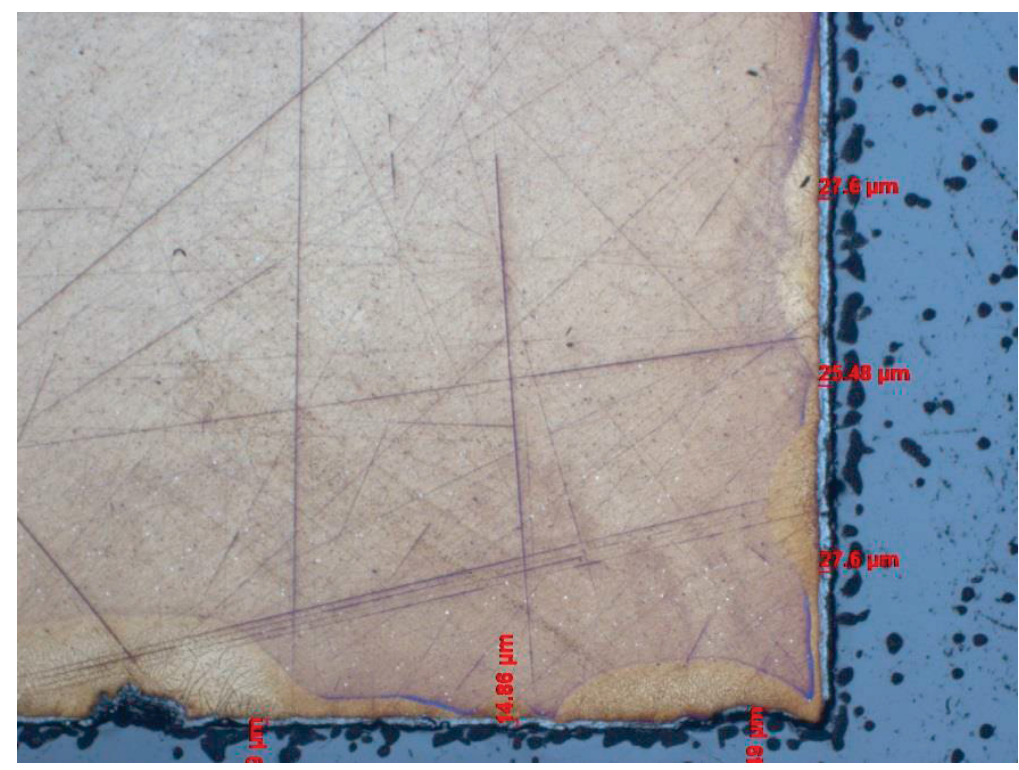

Figure 16. Image from the bottom right corner of DU Cube \#6, treated in the salt bath for 30 minutes and quenched in water. 


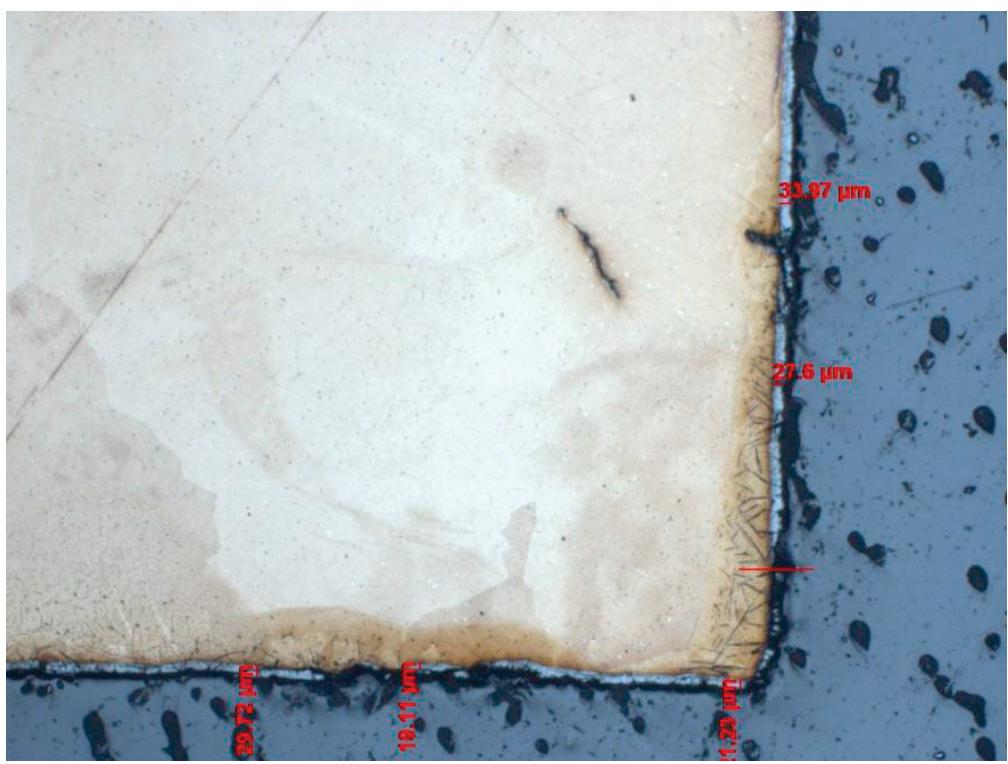

Figure 17. Image from the bottom right corner of DU Cube \#5, treated in the salt bath for 1 hour and quenched in water.

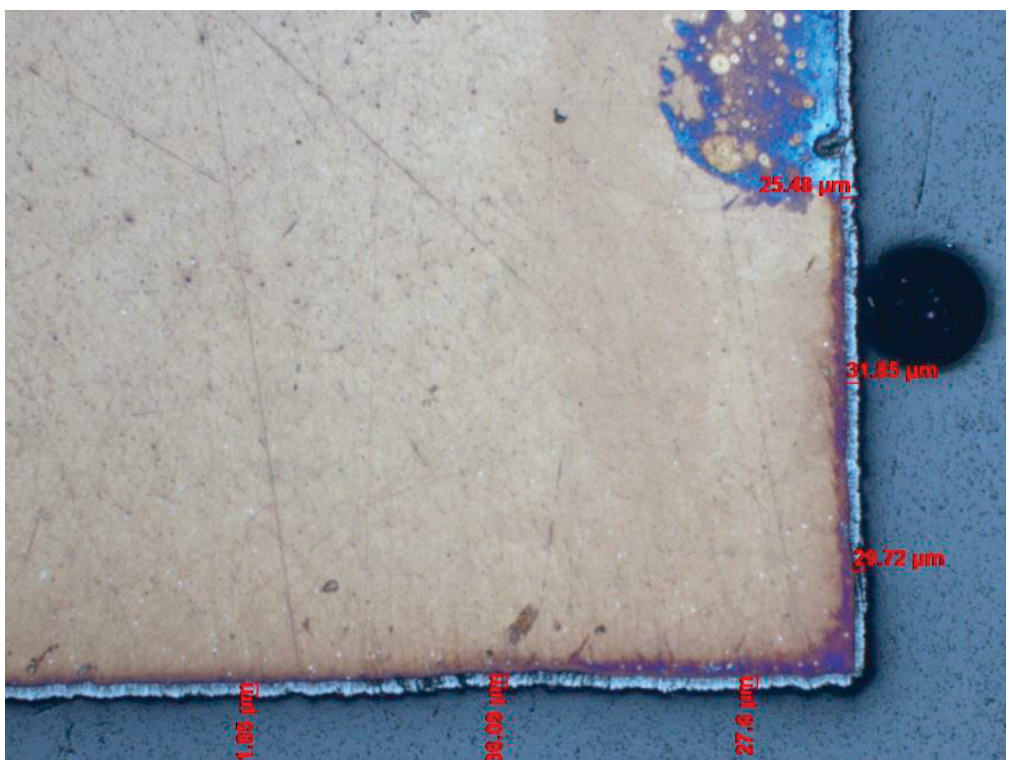

Figure 18. Image from the bottom right corner of DU Cube \#3, treated in the salt bath for 1 hour followed by air cooling. 


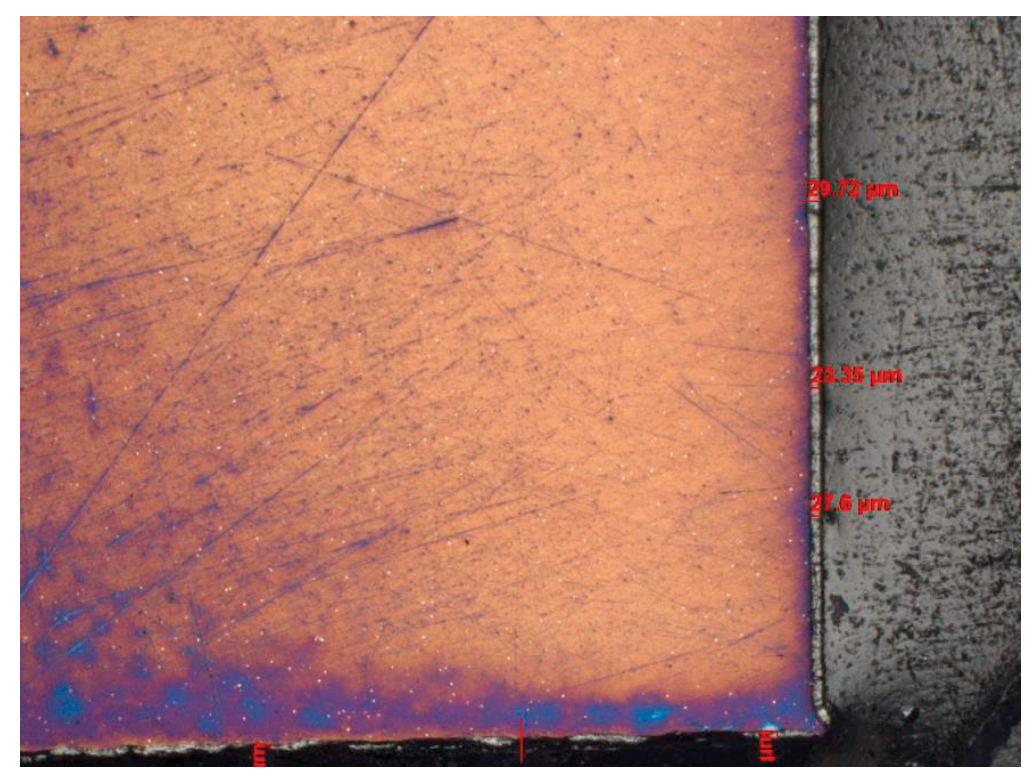

Figure 19. Image from the bottom right corner of DU Cube \#7, treated in the salt bath within a crucible coated with AREMCO Products Pyro Paint 634-ZO for 1 hour and quenched in water.

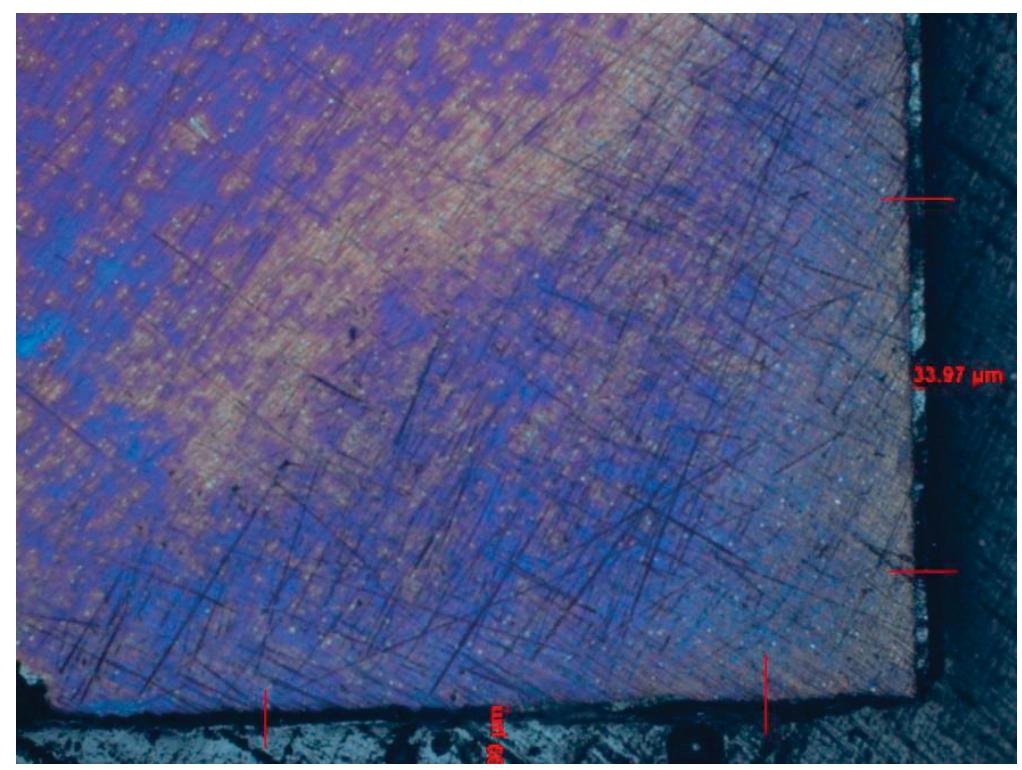

Figure 20. Image from the bottom right corner of DU Cube \#9, suspended for 1 hour in the salt bath (using SS wire and a quartz tube to limit contact with the crucible) and quenched in water. 


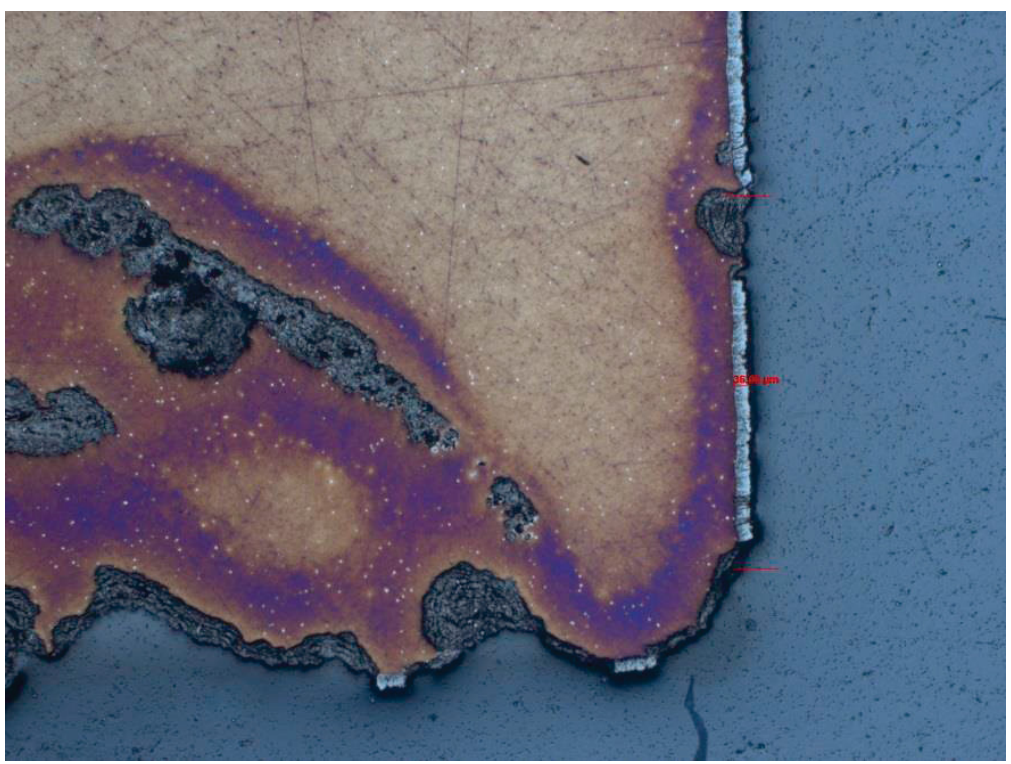

Figure 21. Image from the bottom right corner of DU Cube \#2, treated in the salt bath for 2 hours followed by air cooling.

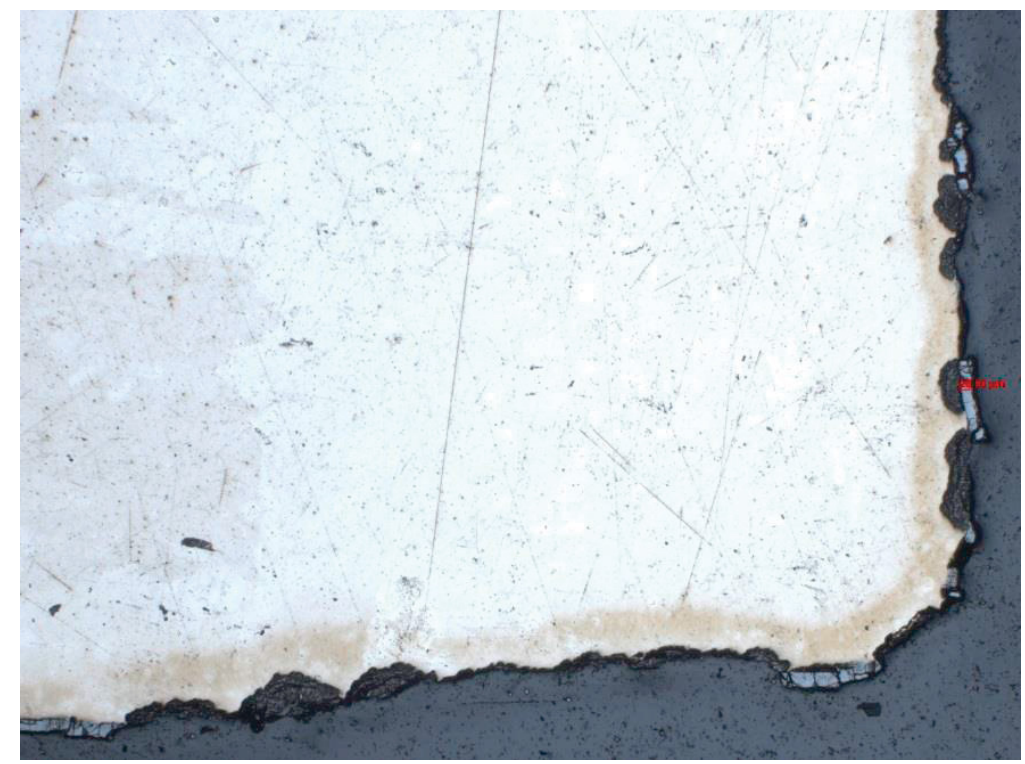

Figure 22. Image from the bottom right corner of DU Cube \#4, treated in the salt bath for 4 hours followed by air cooling.

\section{NEW NA-, LI-, AND K-CARBONATE SALT EXAMINATION}

Three DU samples were used in this experiment. All three samples were generated from the same parent material, ID-1164. Each sample had a corner ground such that orientation of the sample could be maintained for examination. Each sample had the oxide layer removed via a nitric acid cleaning. The samples were then placed in a glove box atmosphere to prevent oxidation. Upon examination after being removed from the glovebox, a noticeable color change had occurred, signifying further oxidation. 
Another nitric acid cleaning was performed just prior to placing samples in the furnace. Photographs were taken of each sample before and after annealing.

TerraPower provided an updated mixture of $\mathrm{Na}-, \mathrm{Li}-$, and $\mathrm{K}-\mathrm{Carbonate}$ salt that presents a lower melting temperature. The ratio of the mixture is $32 \mathrm{wt} \% \mathrm{Li}_{2} \mathrm{CO}_{3}, 33 \mathrm{wt} \% \mathrm{Na}_{2} \mathrm{CO}_{3}$, and $35 \mathrm{wt} \% \mathrm{~K}_{2} \mathrm{CO}_{3}$. The salt mixture was provided pre-melted and solidified in one Inconel crucible and one zirconia crucible. Another zirconia crucible was provided and was filled by INL with the existing Cartecsal salt. All crucibles were placed in an air furnace set at $650^{\circ} \mathrm{C}$ and allowed to come to temperature. Then a sample was placed in each. The two samples in zirconia crucibles were removed at 60 minutes and water quenched. The sample in the Inconel crucible was removed at 30 minutes and water quenched.

After being removed from the quench, a visible oxide layer was present on all three samples. Also visible was a film layer of salt on all samples. Treatments and average rind thickness are shown in Table 5 .

\section{Zirconia Crucibles}

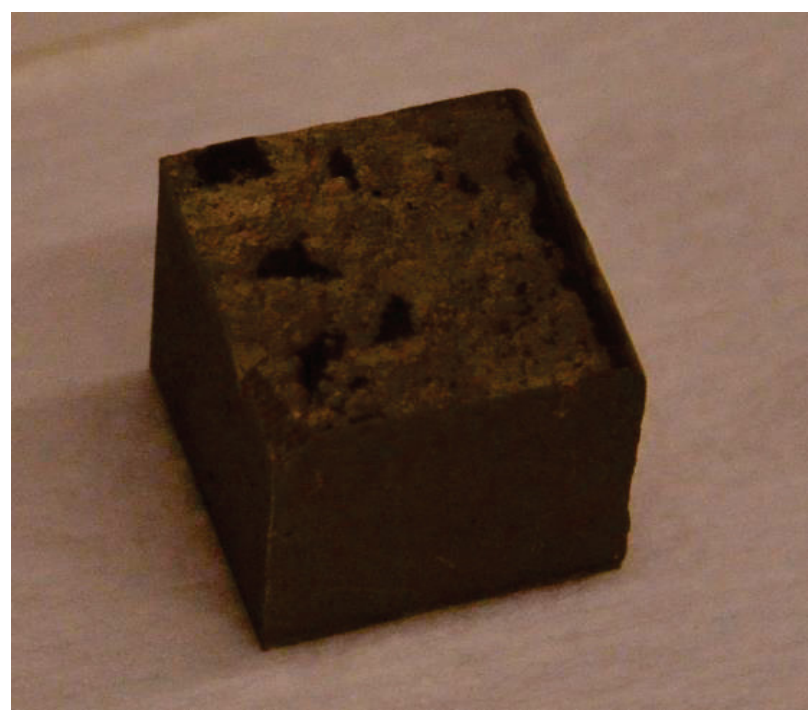

Figure 23. Old salt sample prior to annealing treatment.

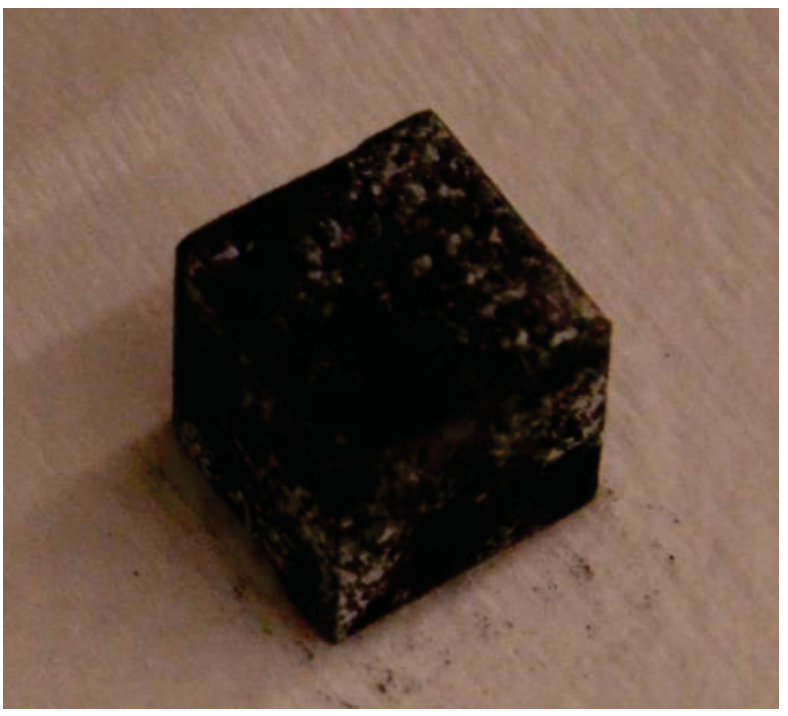

Figure 24. Old salt sample post annealing treatment. 


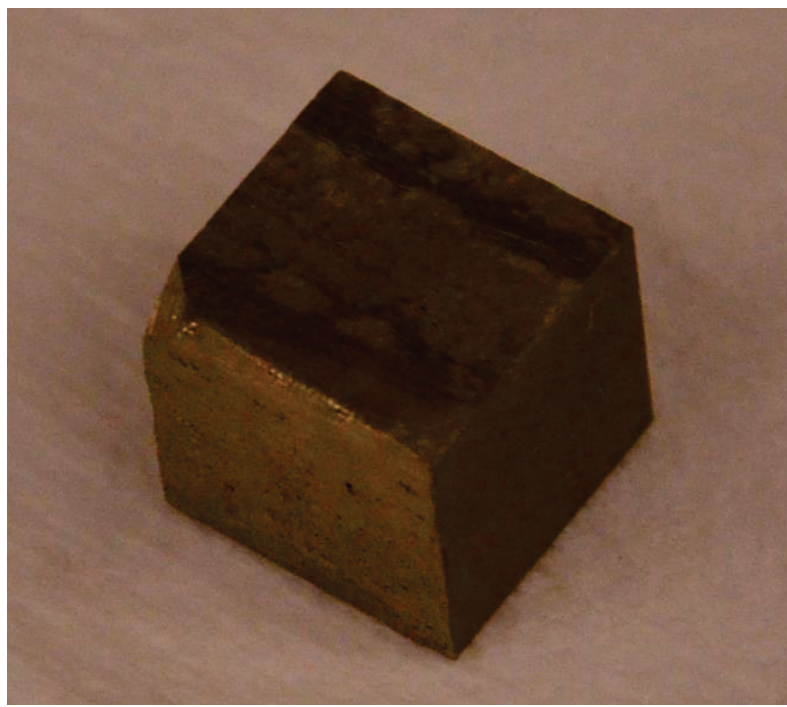

Figure 25. New salt sample prior to annealing treatment.

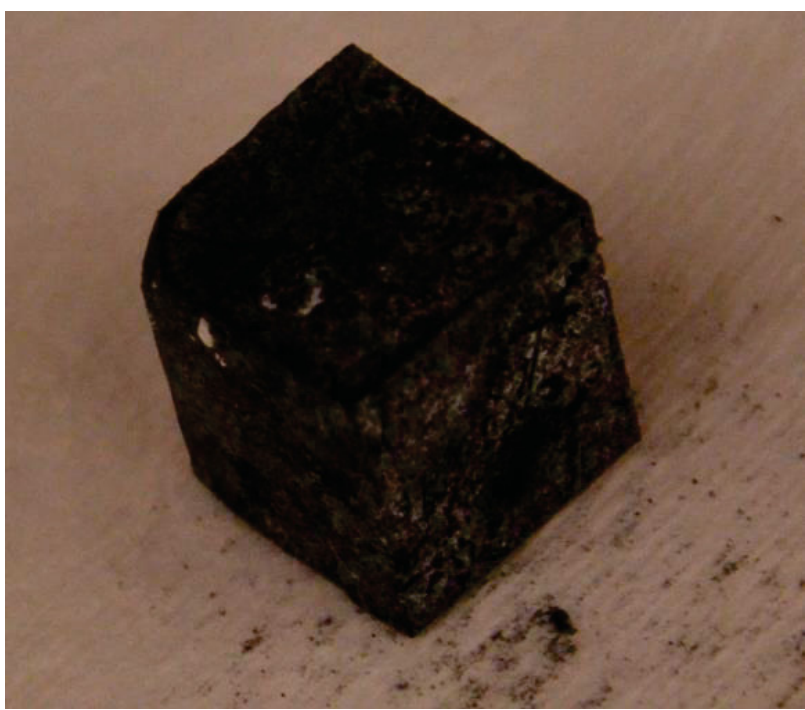

Figure 26. New salt sample post-annealing treatment.

\section{Inconel Crucible}

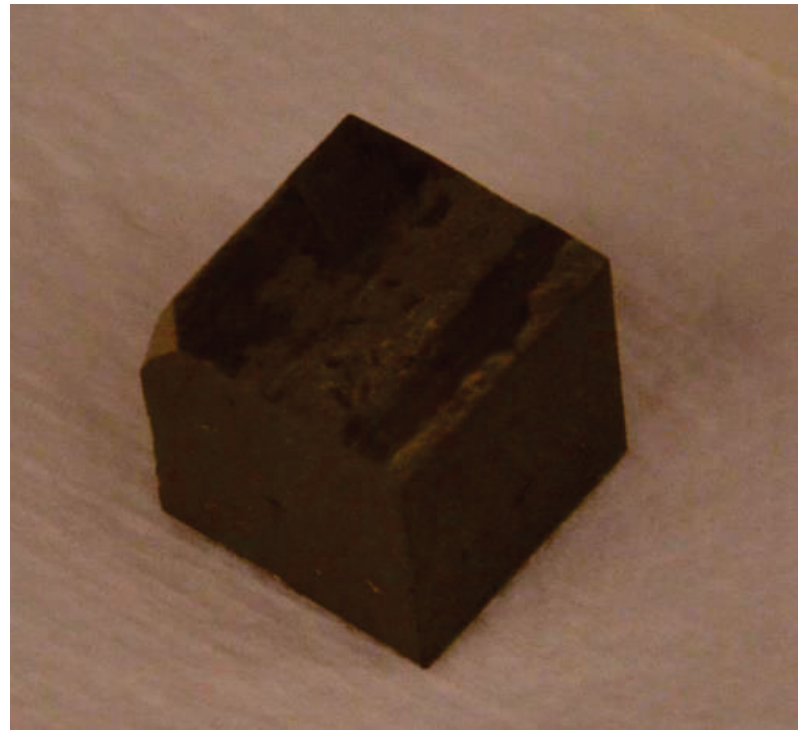

Figure 27. Thirty minute sample prior to annealing treatment.

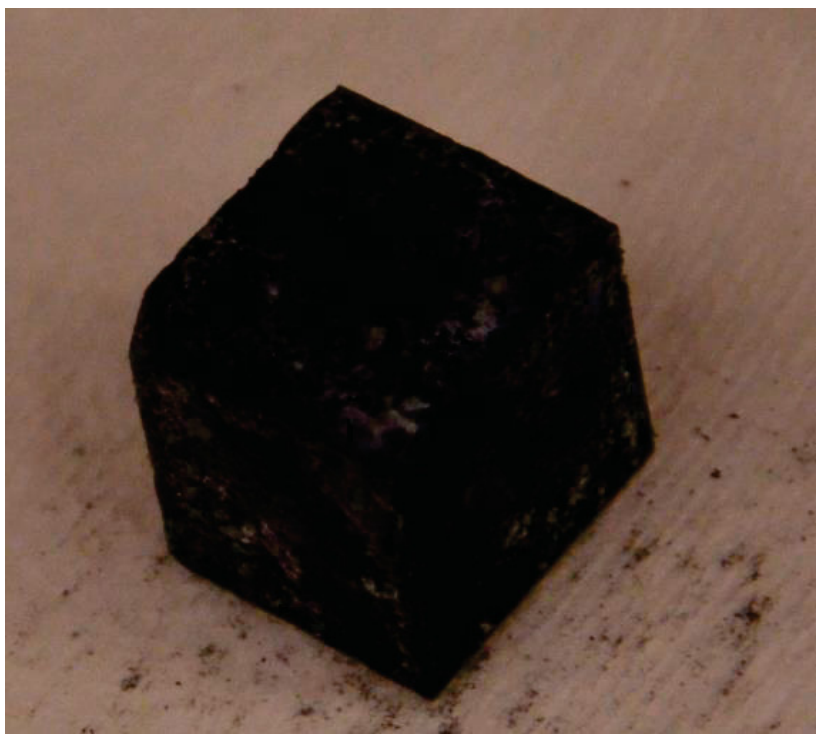

Figure 28. Thirty minute sample postannealing treatment. 
Table 5. Salt treatment description and average rind thickness.

\begin{tabular}{|l|l|}
\hline & $\begin{array}{l}\text { Average Rind } \\
\text { Thickness } \\
(\square \mathbf{m})\end{array}$ \\
\hline $\begin{array}{l}\text { Block 1 } \\
\text { Zr crucible, } \\
\text { Cartecsal salt, } \\
60 \text { min }\end{array}$ & $23.6(\mathrm{n}=4)$ \\
\hline $\begin{array}{l}\text { Block 2 } \\
\text { Zr crucible, } \\
\text { TerraPower } \\
\text { salt, 60 min }\end{array}$ & $17.8(\mathrm{n}=3)$ \\
\hline $\begin{array}{l}\text { Block 3 } \\
\text { Inconel } \\
\text { crucible, } \\
\text { TerraPower } \\
\text { salt, 30 min }\end{array}$ & $26.0(\mathrm{n}=4)$ \\
\hline
\end{tabular}

At the $95 \%$ confidence interval, Block 2 has a smaller rind than Block 3; however, at the $99 \%$ confidence interval, there is no statistical difference between Blocks 2 and 3. The standard deviation for Block 1 measurements is sufficiently large that, statistically, it is not different from Block 2 or Block 3 at the $95 \%$ confidence interval. 